\title{
Parental Bonding and Early Maladaptive Schemas
}

\section{Maria Zafiropoulou*, Penelope-Alexia Avagianou and SidoraVassiliadou}

Department of Pre-School Education, University of Thessaly, Volos, Greece

\begin{abstract}
Objective:Attachment bonds are present throughout one's life and affect interpersonal relationships. Specifically, parent-child relationship is a key factor in the development of personality. Similarly, childhood experiences can lead to configuration and stabilization of cognitive patterns, which play an equally important role in the development and organization of one's personality. The purpose of this study was to examine a) which dimensions of parental behaviour are related to early dysfunctional patterns as reported in the theory of schemas (Young), and b) adolescents' age and gender differences in dysfunctional schemapatterns.
\end{abstract}

Methods: 636 adolescents (11 to 15 years) participated in the study, which completed a questionnaire on basic demographic data, the Schema Questionnaire for Children (SQC) and the Parental Bonding Instrument (PBI).

Results: Results showed that frequency of dysfunctional schemas is affected by dimensions of attachment and that differentiations in dysfunctional schemas are related to adolescent's gender and age.

Conclusion: The present study provided evidence that cognitive patterns formed in childhood are associated to different forms of parental attachment which, in turn, define the way of thinking and behaving in childhood and adulthood.

Keywords: Parental bonding; Early maladaptive schemas

\section{Introduction}

According to the prevailing theory until the mid'50s about the nature of emotional relationships, individuals were searching for contact with other people, only to ensure basics needs such as food or sexual contact [1]. However, after the publication of studies confuting this theory [2], revised his attachment theory, claiming that the type of attachment developed in early infancy will afterwards affect the ability to establish relations, as well as the type and duration of relationships $[2,3]$.

According to the attachment theory, the quality of parentchild relationship plays an important role in the psycho-emotional development of the individual. Since all infants interact with others, every human being develops an attachment bond. Even children who have been abused by a parent or caregiver, generate a kind of attachment. Forms of attachment are established depending on the preexisting experiences and the quality of the relationship with the parent or caregiver [4].

The importance and the role of cognitive patterns were first acknowledged by Beck [5]. He considered that experiences of early childhood modulate basic schemas about the external environment and the self. Additionally Young [6], who developed the schema therapy, underlined the role of early dysfunctional schemas in the existence of psychopathology and personality disorders in adulthood. Based on relevant research findings, Young [6] defined five broad categories of schemas: disconnection and rejection, impaired autonomy and performance, impaired limits, other directness, over-vigilance and inhibition. Each category includes certain Early Maladaptive Schemas (EMS) which incorporates memories, emotions, cognitions and physical senses of the self and of the relationships with others (Table 1). They are formed in early childhood based on early experiences derived mainly from the parental or the caregiver's environment $[7,8]$. Initially, Young identified sixteen early maladaptive schemas and subsequently added two more.

The kind of parental bond could be understood as a conceptual bridge between early relational experiences and early dysfunctional cognitive schemas. Whereas previous studies have measured the effect of early maladaptive schemas on depressive symptoms [9], anorexia nervosa [10], general eating disorders [11], and anxiety [12], as well as the effect of types of attachment on depression [13], data about the association of parental bonding with early maladaptive schemas and the appearance of psychological disorders are rather scarce.

Turner, Rose and Cooper[11] examined the relationship between parental bonding and eating disorders regarding the role of core beliefs as a mediating factor. They found that schemas relating to both shame and dependency may be important in determining the effect that parental bonding has on eating disorder symptoms in female adolescents. Moreover, [14] revealed that the schema domain of disconnection/rejection acted as a mediator in the links between insecure attachment and peer problems. Different types of maladaptive schemas were involved in both types of psychopathology.

The present study aimed to identify possible links between different dimensions of parental bonding and the existence of early maladaptive schemas among the normal population. More specifically, the present study examined the relation between the dimensions of the Parental Bonding Instrument and the fifteen schemas of the Schema Questionnaire for children, as well as gender and age differences on each dimension of parental bonding and early maladaptive schemas.

There had been two working hypothesis. The first referred to the expectation that a diversification between the dimensions of parental bonding and the fifteen early maladaptive schemas would be recorded. This hypothesis was based on relevant finding that more signs of early maladaptive schemas are found among children and adults with insecure attachment/bonding [15].

The second hypothesis, regarding gender differences, assumed that

*Corresponding author: Maria Zafiropoulou, Department of Psychology, University of Thessaly, Greece, Tel: +30 2108075978; E-mail: mzafirop@ece.uth.g Received October 30, 2013; Accepted January 20, 2014; Published January 22, 2014

Citation: Zafiropoulou M, Avagianou PA, Vassiliadou S (2014) Parental Bonding and Early Maladaptive Schemas. J Psychol Abnorm Child 3: 110. doi:10.4172/2329 9525.1000110

Copyright: $(2014$ Zafiropoulou M, et al. This is an open-access article distributed under the terms of the Creative Commons Attribution License, which permits unrestricted use, distribution, and reproduction in any medium, provided the original author and source are credited. 
Citation: Zafiropoulou M, Avagianou PA, Vassiliadou S (2014) Parental Bonding and Early Maladaptive Schemas. J Psychol Abnorm Child 3: 110. doi:10.4172/2329-9525.1000110

Page 2 of 6

\section{Disconnection \& Rejection}

Abusive, traumatic childhoods; unstable family life; rejection and humiliation; feel different and lacking in some way; long periods of insecurity and inconsistent parenting
Mistrust/Abuse Abandonment/Instabiilty EmotionalDeprivation Defectiveness/ Shame Sociallsolation/Alienation
I mpaired Autonomy \& Performance

Often over protected and controlled as children, or neglected and ignored, left alone with no interest shown in their lives; continually undermined and made to feel incompetent, or encouraged to be dependent on others

\begin{tabular}{l} 
Impaired Limits \\
$\begin{array}{l}\text { Internal sense of control not developed; difficulty respecting the rights } \\
\text { of others; families very un- boundaried; children did not have rules }\end{array}$ \\
$\qquad$ Other Directedness \\
\hline $\begin{array}{l}\text { Experienced conditional love; family overly concerned with } \\
\text { appearances; parents focused on their own needs }\end{array}$
\end{tabular}

$$
\text { Over-vigilance and Inhibition }
$$

Strict parental control to gain compliance; ever watchful - waiting for bad things to happen; frightened of severe punishments for expression of feelings

Dependence/Incompetence Vulnerability to Harm Enmeshment

Failure

Entitlement

Insufficient

Self Control/Self Discipline

Subjugation Self-Sacrifice ApprovalSeeking/Recognition Seeking

Negativity/Pessimism Emotionallnhibit on Unrelenting standards/ Hypercriticalness

Punitiveness

Table 1: Domani s and Schemas.

female participants will show more frequent early maladaptive schemas, and a higher correlation to the dimensions of parental bonding. Our second hypothesis was aspired by Shorey [16] findings that women scored higher than men on early maladaptive schemas. Moreover, [17] found that women scored significantly higher than men on three to five early maladaptive schemas.

\section{Methods}

The study involved 636 adolescents, aged between 11-15 years, from different regions of Greece. Of the participants $54.7 \%$ were females and $45.1 \%$ were males both of average socioeconomic status and all at the same educational level according to age.

\section{Instruments}

The Parental Bonding Instrument (PBI) was developed by Parker [18]. The PBI is a self-report questionnaire, which contains 25 items, each of them describing a parental attitude. Two identical forms (one for each parent) were completed by each participant.The questionnaire evaluates two dimensions of parental behaviour, care and protection. Accordingly, there are four types of bonding: optimal bonding (high care - low control), weak or absent bonding (low care - low control), affectionate constraint (high care - high control), affectionless control (low care - high control). The care dimension reflects parental warmth in contrast to indifference and rejection. The over-protection dimension reflects parental control in encouragement of autonomy. In the present study, the Greek-validated PBI [13] was used. Test - retest reliability was found to be 0.76 .

The Schema Questionnaire for Children (SQC) was developed by Stallard [19] and aims to investigate and evaluate the early dysfunctional schemas. SQC assesses 15 early maladaptive schemas proposed by Young. They are grouped in five broad domains which are also presented in Table 1 disconnection and rejection (abandonment, mistrust, emotional deprivation, defectiveness, social isolation), impaired autonomy and performance (dependence, vulnerability, enmeshment, failure), impaired limits (entitlement, insufficient self- control), other directedness (subjugation, self-sacrifice), and over vigilance and inhibition (emotional inhibition, unrelenting standards). The questionnaire was adjusted to Greek by the Laboratory of Developmental Psychology and Psychopathology. Test - retest reliability was found to be between 0.83 and 0.95 .

\section{Procedure}

Schools were selected based on availability and willingness to participate in the research study. After the necessary consent was obtained, participants were asked to complete all questionnaires individually in the presence of the researcher. The overall time of completion was about 45-50 minutes.

\section{Statistical Analysis}

Mean SQC and PBI scores and standard deviations will be calculated in order for the highest and lowest scores to be recorded.

Correlations between early maladaptive schemas and the dimensions of parental bonding will be calculated in order to study existing associations.

Means and Standard deviations of maladaptive schemas according to gender will also be calculated and multivariate analysis will be carried out in order for possible significant effects of gender on maladaptive schemas to be observed.

Finally, analysis variance will be carried out in order for possible significant effects of age on parental bonding dimensions to be observed.

\section{Results}

The mean SQC and PBI scores, as well as the standard deviations were calculated. Regarding early maladaptive schemas, the results indicate that schemas such as unrelenting standards $\left(\mathrm{M}_{1}=3.00\right)$ and emotional inhibition $\left(M_{13}=3.61\right)$ show the highest scores, whereas schemas which indicate abandonment/instability $\left(\mathrm{M}_{4}=1.48\right)$ and emotional deprivation $\left(\mathrm{M}_{7}=1.36\right)$ score extremely low. 
Citation: Zafiropoulou M, Avagianou PA, Vassiliadou S (2014) Parental Bonding and Early Maladaptive Schemas. J Psychol Abnorm Child 3: 110. doi:10.4172/2329-9525.1000110

Page 3 of 6

Accordingly to the two dimensions of the Parental Bonding Instrument (PBI), for both the maternal and the paternal bond, participants categorized their relationship as more caring $\left(M_{\text {maternal }}=28.90, M_{\text {paternal }}=26.25\right)$ than overprotective $\left(M_{\text {maternal }}=16.98\right.$, $\mathrm{M}_{\text {paternal }}=15.87$ ).

\section{Correlations of early maladaptive schemas and dimensions of parental bonding}

Correlations between early maladaptive schemas and the dimensions of parental bonding are presented in Table 2. It was observed that maternal care correlates negatively with most of the schemas. According to the results, when the mother provides proper care, the child doesn't show social isolation /alienation, mistrust /abuse, abandonment /instability and vulnerability to harm. It is also less likely that the child experiences emotional deprivation, self-sacrificed and failure.

However, there is a positive correlation with enmeshment.In addition, maternal protection appears to correlate positively with the following schemas, unrelenting standards/hyper criticalness, social isolation /alienation, mistrust/abuse and abandonment /instability.
On the other hand, overprotection seems to correlate with emotional deprivation, entitlement, enmeshment, self-control /self-discipline and failure. While there was a negative correlation between paternal care and social isolation, mistrust /abuse, vulnerability to harm and failure, additional results revealed that paternal care is connected to excessive enmeshment. Concerning paternal overprotection, it appears that it correlates with all the early maladaptive schemas except subjugation, for which no correlation was observed.

\section{Gender differences and early maladaptive schemas}

Means and Standard deviations of maladaptive schemas according to gender are presented in Table 3. Multivariate analysis indicated significant effect of gender on three of the fifteen maladaptive schemas. Specifically, there are differentiations on schema mistrust/abuse, $\mathrm{F}(1,630)=3.86, \mathrm{p}=$ .050 , dependence/incompetence, $\mathrm{F}(1,631)=4.06, \mathrm{p}=.044$ and insufficient self-control /discipline, $\mathrm{F}(1,628)=3.40, \mathrm{p}=.046$.

\section{Gender differences and parental bonding}

The variance analysis indicated a significanteffectof genderonly on maternal care, $\mathrm{F}(1,633)=5.05, \mathrm{p}=.025$.

\begin{tabular}{|c|c|c|c|c|}
\hline Early maladaptive schemas & Maternal care & Maternal overptotection & Paternal care & Paternal overprotection \\
\hline Unrelenting standards/ypercriticalness & & $.159^{* *}$ & & $.102^{* *}$ \\
\hline Social isolation/Alienation & $-.114^{\star *}$ & $.180^{* *}$ & $-.122^{* *}$ & $.173^{* *}$ \\
\hline Mistrust/Abuse & $-.172^{\star \star}$ & $.162^{* *}$ & & $.177^{* *}$ \\
\hline Abandonment & $-.110^{* *}$ & $.107^{* *}$ & & $.144^{\star *}$ \\
\hline Dependence/Incompetence & & & & $.129^{* *}$ \\
\hline Vulnerability to harm & $-.194^{\star *}$ & . & $-.192^{* *}$ & $.140^{* *}$ \\
\hline Emotional deprivation & $-.112^{* *}$ & $.148^{\star *}$ & & $.173^{* *}$ \\
\hline \multicolumn{5}{|l|}{ Subjugation } \\
\hline Defectiveness/Shame & & & & $.113^{\star *}$ \\
\hline Entitlement & & $.140^{* *}$ & & $.146^{* *}$ \\
\hline Self-sacrifice & $-.103^{* *}$ & $.121^{\star *}$ & & $.145^{\star *}$ \\
\hline Emotional inhibition & & & & $.103^{* *}$ \\
\hline Enmeshment & $.190^{\star *}$ & $.145^{\star *}$ & $.158^{\star *}$ & $.134^{\star \star}$ \\
\hline Self-control/self-discipline & & $.109^{* *}$ & & $.156^{\star *}$ \\
\hline Failure & & $.128^{\star *}$ & $-.119^{\star \star}$ & $.168^{\star *}$ \\
\hline
\end{tabular}

(Only statistically significant correlations $p<.01$, due to large number of variables)

Table 2: Correlation Coefficients (Pearson $r$ ) between early maladaptive schemas and dimensions of parental bonding

\begin{tabular}{|c|c|c|c|c|}
\hline \multirow[t]{3}{*}{ Maldaptive } & \multirow{2}{*}{\multicolumn{2}{|c|}{$\begin{array}{c}\text { Boys } \\
(\mathrm{N}=285)\end{array}$}} & \multicolumn{2}{|c|}{ Girls } \\
\hline & & & \multicolumn{2}{|c|}{$(\mathrm{N}=348)$} \\
\hline & M.S & S.D & M.S & S.D \\
\hline Schema 1 & 3.05 & 1.648 & 2.97 & 1.595 \\
\hline Schema 2 & 2.13 & 1.449 & 2.22 & 1.511 \\
\hline Schema 3 & 1.69 & 1.203 & 1.90 & 1.421 \\
\hline Schema 4 & 1.47 & 1.206 & 1.49 & 1.239 \\
\hline Schema 5 & 2.83 & 1.577 & 2.58 & 1.506 \\
\hline Schema 6 & 2.34 & 1.342 & 2.28 & 1.360 \\
\hline Schema 7 & 1.39 & .966 & 1.34 & 1.046 \\
\hline Schema 8 & 2.56 & 1.568 & 2.45 & 1.505 \\
\hline Schema 9 & 2.20 & 1.377 & 2.11 & 1.265 \\
\hline Schema 10 & 2.36 & 1.558 & 2.41 & 1.560 \\
\hline Schema 11 & 2.44 & 1.504 & 2.54 & 1.558 \\
\hline Schema 12 & 2.62 & 1.661 & 2.62 & 1.731 \\
\hline Schema 13 & 3.46 & 1.799 & 3.73 & 1.771 \\
\hline Schema 14 & 2.15 & 1.588 & 1.90 & 1.524 \\
\hline Schema 15 & 1.44 & 1.023 & 1.45 & 1.129 \\
\hline
\end{tabular}

Table 3: Means and standard deviations of early maladaptive schemas according to gender. 


\begin{tabular}{|c|c|c|c|c|c|c|c|c|c|c|c|c|}
\hline \multirow{2}{*}{$\begin{array}{l}\text { Maldaptive } \\
\text { Schemas }\end{array}$} & \multicolumn{2}{|c|}{$\begin{array}{l}11 \text { years old } \\
(\mathrm{N}=150)\end{array}$} & \multicolumn{2}{|c|}{$\begin{array}{l}12 \text { years old } \\
(N=194)\end{array}$} & \multicolumn{2}{|c|}{$\begin{array}{l}13 \text { years old } \\
(\mathrm{N}=79)\end{array}$} & \multicolumn{2}{|c|}{$\begin{array}{c}14 \text { years old } \\
(\mathrm{N}=64)\end{array}$} & \multicolumn{2}{|c|}{$\begin{array}{l}15 \text { years old } \\
(N=140)\end{array}$} & \multicolumn{2}{|c|}{$\begin{array}{l}16 \text { years old } \\
(\mathrm{N}=2)\end{array}$} \\
\hline & M.S & S.D & M.S & S.D & M.S & S.D & M.S & S.D & M.S & S.D & M.S & S.D \\
\hline Schema 1 & 3.16 & 1.788 & 2.03 & 1.640 & 3.19 & 1.618 & 2.78 & 1.578 & 2.83 & 1.388 & 2.00 & 0.00 \\
\hline Schema 2 & 1.86 & 1.361 & 2.39 & 1.667 & 2.46 & 1.663 & 2.00 & 1.323 & 2.17 & 1.229 & 2.00 & 1.414 \\
\hline Schema 3 & 1.72 & 1.259 & 1.87 & 1.473 & 2.08 & 1.474 & 1.71 & 1.422 & 1.66 & 1.018 & 3.50 & .707 \\
\hline Schema 4 & 1.73 & 1.496 & 1.49 & 1.272 & 1.34 & .973 & 1.38 & 1.195 & 1.34 & .927 & 1.00 & 0.00 \\
\hline Schema 5 & 2.74 & 1.640 & 2.86 & 1.616 & 2.77 & 1.510 & 2.75 & 1.500 & 2.33 & 1.322 & 2.50 & 2.121 \\
\hline Schema 6 & 2.11 & 1.342 & 2.35 & 1.425 & 2.72 & 1.377 & 2.14 & 1.158 & 2.29 & 1.299 & 3.00 & 1.414 \\
\hline Schema 7 & 1.56 & 1.322 & 1.34 & .996 & 1.42 & 1.008 & 1.14 & .583 & 1.23 & .693 & 1.00 & 0.00 \\
\hline Schema 8 & 2.07 & 1.621 & 2.65 & 1.590 & 2.56 & 1.631 & 2.34 & 1.574 & 2.10 & 1.187 & 1.00 & 0.00 \\
\hline Schema 9 & 2.36 & 1.392 & 2.23 & 1.459 & 2.42 & 1.402 & 1.60 & .862 & 1.87 & .977 & 2.00 & 1.414 \\
\hline Schema 10 & 2.66 & 1.695 & 2.43 & 1.625 & 2.59 & 1.605 & 2.09 & 1.318 & 2.06 & 1.326 & 1.50 & .707 \\
\hline Schema 11 & 2.34 & 1.571 & 2.73 & 1.645 & 2.67 & 1.517 & 2.17 & 1.474 & 2.42 & 1.341 & 1.50 & .707 \\
\hline Schema 12 & 2.89 & 1.876 & 2.76 & 1.788 & 2.90 & 1.653 & 2.28 & 1.341 & 2.12 & 1.381 & 1.50 & .707 \\
\hline Schema 13 & 4.14 & 1.783 & 3.73 & 1.779 & 3.65 & 1.791 & 3.88 & 1.768 & 2.73 & 1.516 & 3.50 & 2.121 \\
\hline Schema 14 & 2.13 & 1.720 & 2.31 & 1.748 & 2.13 & 1.436 & 1.80 & 1.416 & 1.51 & 1.027 & 3.00 & 2.828 \\
\hline Schema 15 & 1.53 & 1.235 & 1.53 & 1.199 & 1.57 & 1.173 & 1.22 & .800 & 1.23 & .661 & 2.50 & 2.121 \\
\hline
\end{tabular}

Table 4: Means and standard deviations of early maladaptive schemas according to age.

\section{Age differences and early maladaptive schemas}

Means and Standard deviations of maladaptive schemas according to age are presented in Table 4. Participants were divided according to age per year (11years, 12years, etc). ANOVA pointed out a significanteffectofage on mostmaladaptive schemas. Thus, the child's agewas connected withsocial isolation/alienation, $\mathrm{F}(4,629)=2.94$, $\mathrm{p}$ $=.012$, thevulnerabilityto harm, $\mathrm{F}(4,629)=2.50, \mathrm{p}=.030$, emotional deprivation, $\mathrm{F}(4,627)=2.39, \mathrm{p}=.037$, subjugation, $\mathrm{F}(4,628)=3.39$, $\mathrm{p}=.005$, thedefectiveness/ shame, $\mathrm{F}(4,628)=5.31, \mathrm{p}=.000$, and the entitlement, $\mathrm{F}(4,627)=3.08, \mathrm{p}=.009$. Also, self-sacrifice, $\mathrm{F}(4,629)$ $=2.27, \mathrm{p}=.046$, emotionalinhibition, $\mathrm{F}(4,628)=4.74, \mathrm{p}=.000$, enmeshment, $\mathrm{F}(4,624)=10.402, \mathrm{p}=.000$, insufficientself-control/ discipline, $\mathrm{F}(4,626)=5.05, \mathrm{p}=.000$ and failure, $\mathrm{F}(4,628)=2.80, \mathrm{p}=$ .016 .

\section{Age differences and parental bonding}

The variance analysis indicated a significant effect of age on both parental bonding dimensions. More specifically, maternal care dimension, $\mathrm{F}(4,631)=11.28, \mathrm{p}=.000$, maternal protection, $\mathrm{F}(4,631)$ $=6.67, \mathrm{p}=.000$, as well as paternal care, $\mathrm{F}(4,625)=9.07, \mathrm{p}=.000$ and paternal protection, $\mathrm{F}(4,625)=6.98, \mathrm{p}=.000$. Pearson's $r$ (correlation) was used as an effect size. R scores obtained showed a medium to large effect size, with $\mathrm{r}$ varying from $0.24-0.42$ throughout [20].

\section{Discussion}

The present study aimed to examine the relationship between early maladaptive schemas and parental bonding in normal population. The negative correlation observed among maternal care and most of the early maladaptive schemas verifies the expectation that proper early maternal care provides the child with immunity to social isolation, mistrust and vulnerability. It is also less likely that the child experiences emotional deprivation, self-sacrificed and failure. In particular, motherchild relationship plays a key role in the person's social behaviour and attitude to future relationships. When the mother shows affection and interest, as well as constant control, the child seeks to build lasting relationships which are characterised by trust to others, free expression of feelings and fearlessness of loneliness. These factors advocate good mental health and build positive relationships. When, on the other hand, mother-child relationship is characterized by overprotection and lack of affection, emotional stability disappears. The child is socially isolated; he/she fears abandonment or abuse and feels emotionally vulnerable. The above findings are in accordance to research studies such as the one conducted by Matsuoka [21] who showed that total attachment style was predicted by scores of paternal and maternal bonding. Thus, the adults' attachment style was predictable of early experiences but there existed some gender differences.

Paternal bonding patterns are equally connected to the shaping of early maladaptive schemas. As shown in the present results, paternal overprotection appeared to correlate with all the early maladaptive schemas. Apparently, therefore, dominant fathers, who exert control over every aspect of a child's life, seem to have a negative effect on the child's socialization; he avoids close contact with others and does not dare to express his opinions and feelings. On the contrary, fathers who care for their child, providing security (not overprotection) strengthen the child's sociability and his/her ability to establish relations without fear of negative consequences or treason.

Differences between maternal and paternal bond observed in the present study are confirmed by previous research findings. Specifically, mothers have been judged as more caring than fathers, a fact which has been regarded as a global phenomenon [22]. In addition, Main and Weston (1981), noted in their research, that the same child may be experiencing the relationship with the mother as safe, while the relationship with the father as insecure.

Differences between maternal and parental relationship can be explained by social beliefs that characterize each part separately. Specifically, mothers, who -in most cases- are the primary caregivers, can more freely express their feelings and affection. In contrast, fathers, taking the male role, are suitable to teach the child discipline and success in various areas of social life.

As far as the role of gender and age on early maladaptive schemas and dimensions of parental bonding are concerned it was observed that gender correlates with the feeling of mistrust, dependence and self-discipline experienced by the child. In particular, girls are feeling enmeshment more frequently, while boys experience more dependence and lack of self-control/self-discipline. This could be interpreted by the stereotypical roles of each gender, where girls show schemas related to emotions, while boys schemas involve power and sovereignty. Similar findings revealed little differences between boys and girls on the emergence of early maladaptive schemas [23]. Other surveys, however, which have been conducted in adult population, mark strongly the 
gender differentiation in the appearance of early maladaptive schemas [16]. It could, therefore, be argued that the differences based on gender, may appear more often in older children.

Furthermore, girls appeared to report more intense affection and empathy on behalf of their mothers, whereas, boys reported much less emotional involvement. In an attempt to interpret the finding it could be argued that since both mother and daughter belong to the female gender, the creation of a more intimate bond is not only easier but also socially "correct". Boys, on the other end, in an attempt to adapt to social norms, tend to not accept strong emotional involvement. The findings may also reflect different perceptions of gender (male and female) in the parental relationship. Early maladaptive schemas appear to be affected by the age of the child. Apparently, very young adolescents experience a greater degree of emotional deprivation and criticism. They avoid expressing their feelings; they are not autonomous and have difficulties to discipline their actions, feelings and thoughts. In contrast, older adolescents (15 years) experience a higher degree of social isolation, vulnerability and subjugation in social and non-social imperatives. These findings contradict our hypothesis that older children will reveal a greater rate of early maladaptive schemas. Also, contrary to previous studies Stallard, [23], no differences were found in the emerge of early maladaptive schemas in children aged 11 to 15 years.

However, the present results may be justified taking into account that children during adolescence acquire a better understanding of personal responsibility and independence. At the same time, it must be noticed that in certain phases of child development schemas are not seen as dysfunctional.

This study attempted to connect the early maladaptive schemas with the dimensions of parental bonding, providing empirical support of the role of maternal and paternal bond in configuration of early maladaptive schemas, at a critical developmental period of children.

Clearly, the results may be useful in the development of appropriate educational and preventative programs to avoid stabilization of early maladaptive schemas. Therefore, the need of a stable parent- child relationship is essential for the development of personality and mental stability of the child.

At the same time, this study contributes in the finding of appropriate strategies to deal with dysfunctional schemas, such as parental counselling, individual or family therapy and techniques of conflict resolution.

As cognitive theory suggests schemas play an important role in the maintenance of chronic problems. Maladaptive schemas are presumed to originate early in life creating, subsequently, vulnerability for psychological problems. However, research on maladaptive schemas in younger populations has lagged far behind that of adult samples [24]. Nonetheless, it is clinically important that therapists develop strategies for changing early maladaptive schemas.

Changing maladaptive cognitions is a primary focus of CognitiveBehaviouralTherapy (CBT), the best researched, the fastest growing and the best empirically validated psychotherapeutic approach [25]. According to [26] "the overall purpose of CBT is to increase selfawareness, facilitate better self-understanding, and improve self-control by developing more appropriate cognitive and behavioural skills". This is accomplished with the aid of a number of certain behavioural and cognitive intervention techniques such as psycho-education and problem formulation; identification, monitoring of thoughts, feelings and behaviour; challenging and testing of cognitions; developing new cognitive skills; learning alternative ways to manage unpleasant emotions; learning new behaviours; target settings and home-based practice assignments, and positive reinforcement [27].

Further research should focus on the specific influence of parental bonding and early maladaptive schemas on future relationships. In conclusion, the information obtained from this survey highlights the importance of primary relationships in the mental development and social adjustment of the individual, parental bonding being a key source of psychopathology.

\section{References}

1. Bowlby J (1979) Das Gluck und die Trauer. Herstellung und Losungaffektiver Bindungen. Stuttgart: Klett-Cotta.

2. BowlbyJ (1982) Attachment and loss: Vol. 1. Attachment. New York: Basic Books.

3. Waters E, Merrick S, Treboux D, Crowell J, Albersheim L (2000) Attachment security in infancy and early adulthood: a twenty-year longitudinal study. Child Dev 71: 684-689.

4. Bowlby J (1988) A secure base: Parent-child attachment and healthy human development.New York: Basic Books.

5. Beck AT, Dozois DJ (2011) Cognitive therapy: current status and future directions. Annu Rev Med 62: 397-409.

6. Young JE (1990) Cognitive Therapy for Personality Disorders: a schemafocused approach. Sarasota FL: Professional Resource Exchange.

7. Hoffart A, Sexton H, Hedley LM, Wang CE, Holthe H, et al. (2005) The structure of maladaptive schema: a confirmatory factor analysis and a psychometric evaluation of factor-derived scale. Cognitive Therapy and Research 29: 627644

8. Young JE, Klosko JS, Weishaar ME (2010) Treatmentregimens.A guidefor the therapist. Athens: Pataki.

9. Shah R, Waller G (2000) Parental style and vulnerability to depression: the role of core beliefs. J NervMent Dis 188: 19-25.

10. Leung N, Thomas G, Waller G (2000) The relationship between parental bonding and core beliefs in anorexic and bulimic women. Br J ClinPsychol39 : 205-213.

11. Turner HM, Rose KS, Cooper MJ (2005) Parental bonding and eating disorder symptoms in adolescents: the meditating role of core beliefs. Eat Behav 6: 113-118.

12. Murray LK (2003) Do schemas mediate the relationship between parenta bonding and psychopathology in adulthood? Unpublished doctoral thesis. University of Edinburgh, Edinburgh, Scotland.

13. Avagianou PA, Zafiropoulou M (2008) Parental bonding and depression: personality as a mediating factor. Int J Adolesc Med Health 20: 261-269.

14. Roelofs J, Onckels L, Muris P (2013) Attachment Quality and Psychopathological Symptoms in Clinically Referred Adolescents: The Mediating Role of Early Maladaptive Schema. J Child Fam Stud 22: 377-385.

15. Wright MO, Crawford E, Del Castillo D (2009) Childhood emotional maltreatment and later psychological distress among college students: the mediating role of maladaptive schemas. Child Abuse Negl 33: 59-68.

16. Shorey RC, Anderson SE, Stuart GL (2012) Gender differences in early maladaptive schemas in a treatment-seeking sample of alcohol-dependent adults. Subst Use Misuse 47: 108-116.

17. Shorey RC, Stuart GL, Anderson S (2013) Do gender differences in depression remain after controlling for early maladaptive schemas? An examination in a sample of opioid dependent treatment seeking adults. ClinPsycholPsychother 20: $401-410$

18. Parker G, Tupling H, Brown LB (1979) A parental bonding instrument. British Journal of Medical Psychology 52: 1-10

19. Stallard P, Rayner R (2005) The development and preliminary evaluation of a Schema Questionnaire for children (SQC). Behavioural and Cognitive Psychotherapy 15: 252-272. 
Citation: Zafiropoulou M, Avagianou PA, Vassiliadou S (2014) Parental Bonding and Early Maladaptive Schemas. J Psychol Abnorm Child 3: 110. doi:10.4172/2329-9525.1000110

Page 6 of 6

20. Cohen J (1992) A power primer. Psychol Bull 112: 155-159.

21. Matsuoka N, Uji M, Hiramura H, Chen Z, Shikai N, et al. (2006) Adolescents' attachment style and early experiences: a gender difference. Arch WomensMent Health 9: 23-29.

22. Canetti L, Bachar E, Galili-Weisstub E, De-Nour AK, Shalev AY (1997) Parental bonding and mental health in adolescence. Adolescence 32: 381-394.

23. Stallard P (2007) Early maladaptive schemas in children: Stability and differences between a Community and a Clinic referred sample. Clinical Psychology and Psychotherapy 14: 10-18.
24. Cole DA, Ciesla JA, Dallaire DH, Jacquez FM, Pineda AQ, et al. (2008) Emergence of attributional style and its relation to depressive symptoms. J AbnormPsychol 117: 16-31.

25. Beck AT, Dozois DJ (2011) Cognitive therapy: current status and future directions. Annu Rev Med 62: 397-409.

26. Stallard P (2002) Think Good-Feel Good. A Cognitive Behaviour Therapy Workbook for Children and Children and Young People. West Sussex: John Wiley \& Sons.

27. Stallard P (2005) Think Good-Feel Good. Using CBT with children and young people. West Sussex: John Wiley \& Sons. 